\title{
Development of Prototype Community for Improve the Quality of Life of Leprosy Patient in Mealao Colony, Thailand
}

\author{
Sirichom Pichedboonkiatrst
}

\begin{abstract}
This study aims to develop the participation of the community to enhance the quality of life of those who receive the impact of a parent or relative who is a patient of leprosy settlement in Mae Lao, Thailand. The total of population is $\mathbf{5 0 .}$ Data collecting was in-depth interviews and observation. Statistics used were frequency, percentage, mean and standard deviation. The results found that the yield and the product of the community related to the consumption of such vegetables and fruits as well as the processing of agricultural products, etc. are often not recognized and is offensive to consumers. So Stakeholders resolved to enhance the production of a professional and a consumer product that is about as exhaustible supplies not harmful to the health of consumers and to the external body.

For the practice professional skills with four careers: 1) Balsam and scented teas absorb odors 2) Bio-composting 3) The water multi-purpose solution, and 4) Doormat from natural materials by application of the Sufficiency Economy philosophy as a guide to promote professional skills. For assessment of all products have found that the overall standard was good, and also the satisfaction of all stakeholders towards the product's target group showed that overall satisfaction with the high level products.
\end{abstract}

Index Terms-Leprosy, potential, economic sufficiency, quality of life.

\section{INTRODUCTION}

Stated and problems, including political and social context of the patient's leprosy settlement in Mae Lao found the urgent need to improve the quality of life that can live happily in society. Need to improve the quality of life, including physical, psychological, emotional, social, and economic. To ensure quality of life and well-being can help themselves and their relationship with the surrounding communities happily therefore; government support is important and essential that leprosy patients were waiting for hope and the opportunity to be developed as a community with others and excel in all aspects especially the psychological and social of them. Moreover, another problem encountered which is assistance from the government and the private sector to help was very little such as the items donated because of due to fears of the spread of leprosy, and other diseases that may occur. Including guidelines for state aid that focuses on participation, often find that most of the development in the implementation of various development projects that State into a target area by the community to participate, just bring the state into action. It is usually found that such action did not succeed much. Especially for the continuity and sustainability of the operations of the various groups are generally established by the state. And when the project is completed by a set time period. Group was dissolved by the lessons and important question that arises is. And issues of the community, the strength of the community that much. Current developments in the later period, to focus on issues of civil society strong. We believe that if the community is strong. Would result in the community can participate in more development, and lead to a more sustainable development.

Of the circumstances mentioned above. Settlement in Mae Lao community is ready to be developed into a strong as well as the acceptance of a normal person in the community with leprosy patients. This would not accept the belief that leprosy is a serious disease. Leprosy is a disease that causes disgust in society. Impact on the lives of people living in Mae Lao settlement in spite of the disease has been controlled and stops it spreading, and has been closely monitored by health officials of the Office of Disease Prevention and Control 10, so different from the people in the urban settlement in Mae Lao greatly in terms of social lifestyle, economic and cultural studies. This may impact negatively on their lives both in social and cultural behavior and quality of life, so the local authorities should be considered important and necessary to require the participation of the community. Particular institution, including faculty, students, government agencies and the private sector to be involved truly elevate the quality of life of people in the settlement Mae Lao. Sustainability of the concept of sufficiency economy as a guideline in life based on a balance between cultures, quality of life and environment, so the researchers from the University of Technology Lanna, ChiangRai who are awareness and interest in research. Community Development application underlying the potential to enhance the quality of life of patients with leprosy settlement in Mae Lao, which is ready to face the problems that can occur and need to change crisis into opportunities for leprosy patients. In order to provide patients with leprosy settlement in Mae Lao and family quality of life improved without having to modify their traditional lifestyle. It will focus on the application of sufficient economy. By reducing expenditure, increasing revenue by siphons, based on a self-sustainable.

\section{METHODS}

This study is a qualitative research and participatory action 
research (PAR). The participation in community development. The researchers will study the learning process with the participation of the community by observation, focus group and interview unofficially from the planning stages, process of decision making, procedures, and the evaluation process of the community in three aspects: the additional income, occupational, and health. For raise the quality of life of those affected by their parents or relatives who are patients of leprosy settlement in Mae Lao. Using criteria of quality of life indicators in the Office of the National Economic and Social Development. Criteria which measure four aspects: occupational supplementary income health and participation in community development. [1] Besides the focus group was discussion about the criteria for the quality of life of three aspects based on a natural application of the sufficiency economy philosophy.

Population was the specified number of 25 households in which the participation of officials from the Office of Disease Prevention and Control 10 is considered a household of targeted education in a safe distance and cannot connect to others. The collecting of the research data are questionnaire which assessing progress in skills development in the four professional groups that researchers have created a tool to measure progress before and after the training skills. For test the quality of the product in four professional groups in the field of beauty, durability, safety standards and use. Including the satisfaction of consumers and other stakeholders in the field of beauty, durability, safety standards and utilization. The statistics used for data analysis in qualitative research is to describe the frequency and percentage of basic information about the capabilities and knowledge of the target audience. For statistical data analysis used in quantitative research were frequency, percentage, mean and standard deviation.

\section{RESULTS AND DISCUSSIONS}

A development with community participation to improve the quality of life of those affected by their parents or relatives who are patients of leprosy settlement in Mae Lao, Chiang Rai Province. Analysis capabilities and marketing strategies targeted at education found that those with the need for all sectors to support and enhance the quality of their lives such as other social groups or communities, especially the potential for a career in the community. Including all sectors related to the dissolution of the term "settlement in Mae Lao" to reassure us about the adoption and get equal opportunities in society. This may be due. Settlement in Mae Lao was originally the founder of the settlement of this government is to be a source of renewal leprosy patients by virtue of state land for allotment to such groups can live and work without any cost, however they cannot exchange it, but to live forever Meanwhile, the area is the responsibility of state land. Organization for the advancement of economic and population growth make immigrants vulnerable groups living in the area a lot. The area of such a diverse group of death came to live in this area, such as patients with leprosy, children and relatives of patients with leprosy, people from other areas who made the land to the farmers. As a result, these groups are constructed as all leprosy patients who make them a social impact. Because the general public is not acceptable and undesirable because they are mistaken for leprosy, a contagious disease and not everyone wants to get close, or ostracized. Of inferiority and a sense of frustration that makes those who have been affected by their parents or relatives who are patients of leprosy settlement in Mae Lao, both among the first and among the 11 to be a sense of privacy which Mae Lao settlement owner is to develop unity is to be recognized by the people in their own society. Therefore, the total power by the creative community to join the community in all stages of development and a strong commitment to equality of opportunity in society by starting initiate sufficiency economy philosophy as a guide of lifestyle and settlement activities in Mae Lao community. This is consistent with the concept of Prakorn Supinanon (2008) [2] mentioned learning participation and cooperation to resolve the differences in the group and everyone can work together very well. Having regard to the principles of human intelligence that shows that we each have a unique ability to be able to discover the true capabilities are. If you have been encouraged and supported in the right way, it makes that person can show that their ability to get out. Because when the people join the group. We can learn from their own group that we have in any aptitude and training played a role together in a social group. Learn to work together and live together in a society where each person is an important part at all. Because each of us has different capabilities. But when living together in society, then society will contribute to the development has progressed well, with so gathered a team and be able to live together happily in society.

Applied the concept of sufficiency economy to raise the quality of life of those affected by their parents or relatives who are patients of leprosy settlement in Mae Lao. The importance of applying the concept of sufficiency economy as a way of life, so it is important to have knowledge and understanding about the philosophy of sufficiency economy of targeted education. In terms of perceptions about sufficiency economy philosophy and behavior, lifestyle of sufficiency economy. The study found that overall the most perceptions and behavior, lifestyle of sufficiency economy philosophy in all aspects of 50 percent over the meaning and importance of the sufficiency economy philosophy, elements of the philosophy of sufficiency economy, the sufficiency economy philosophy to practice, and benefits of the sufficiency economy philosophy as summarized in Fig. 1.

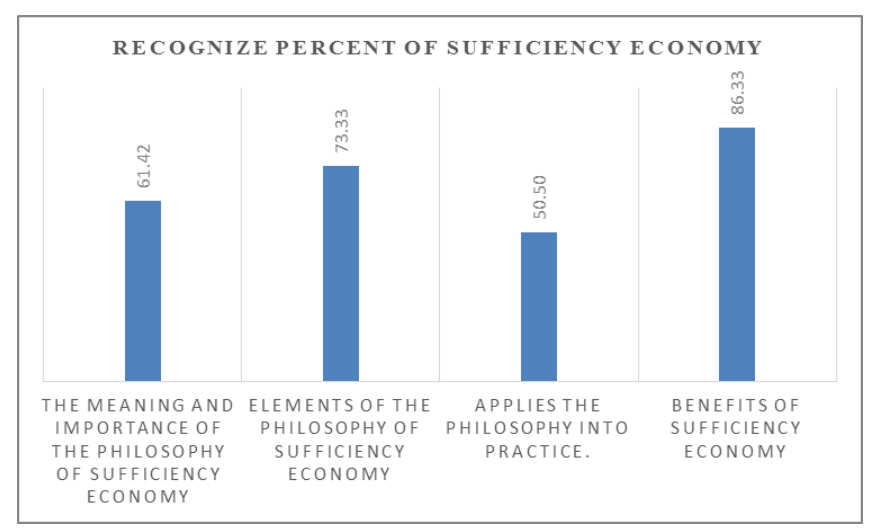

Fig. 1. Recognize percent on sufficiency economy of the target group. 
This may be due Thailand's recognition of the grace of God is His Majesty King Bhumibol Adulyadej [3]. Especially during the economic crisis in Thailand year 1997, while it ascribes stagnant economic growth, poverty, and inequality in society higher. Rethink all sectors and activities and live in the way of balance. The government recognizes the importance of sufficiency economy philosophy. Especially economic development to keep pace with globalization. Moreover, the need to strengthen the hearts of the nation with a sense of integrity and balance to support the rapid and extensive changes in both the social and cultural environment of the outside world as well. The importance of such a settlement in Mae Lao villagers and people realize the importance of the sufficiency economy philosophy. Including the disadvantaged, as feelings and environment in society, they have a habit of life that no negligence on the participation of the community settlement in Mae Lao achieves learning to rely on yourself and your friends to share together in society. This is consistent with the concept of Sumelt Tantivejakul (2006) [4] mentioned the importance and benefits of sufficiency economy of His Majesty. People of all levels who want to turn back the central route (Middle) to life. Using the principle of self-reliance five reasons.

1) Self mentally. To complete and requires a strong mind are conscious that they are self-reliant. So that should be the driving force for the battle of life with honesty mental. Although it may not be successful but should be discouraged.

2) Social self. Each local community should strengthen cooperation to support one another. The knowledge that has been transcribed and published for the benefit of each other

3) Autonomous natural resources are encouraged to bring the potential of local people to seek natural or local materials available to the maximum benefit. This resulted in the development of the country as well. The best thing is to apply local knowledge (Local Wisdom), which are abundant in the country.

4) Autonomous technology should encourage the study were tested to obtain the new technologies that are consistent with the social terrain and Thailand which is important and can be used to perform properly.

5) Self-reliance in the economy means to address their own basic if even without money; they also have their own local fish, fruit and vegetables for sustenance, and can lead to the development of the national economy at macro level.

Learning about the basic knowledge and behavior, lifestyle of sufficiency economy philosophy. Including analysis of the potential for enhancing professional skills, as well as to the practical skills to meet the needs and possibilities for the development of model community education goals. Both the self-assessment before and after joining the professional skills training and assessment standards, the group has produced and developed the concept of sufficiency economy, and satisfaction with the product of stakeholder groups in the community that residents Mae Lao settlement are ready in all aspects in the context of the community. Potential behavior and lifestyle of the community settlement Mae Lao whose have a sense of ownership the community together highly regarded as strengths to develop a model community to enhance the quality of life of the target group study of the concept of sufficiency economy philosophy in the future, based on a participatory process of all sectors to encourage the continuation and sustainable. The Self-assessment before and after joining the professional skills of the target group, The overall score of the six evaluations found that assessment after training than before training career was high professional skills in all aspects which have passed more than half of the total score, and also assessment of the target product. All products have found that the overall standard was good. Besides the satisfaction with the product of all stakeholders towards the product's target group showed that overall satisfaction with the high level products as summarized in Fig. 2-Fig. 4.

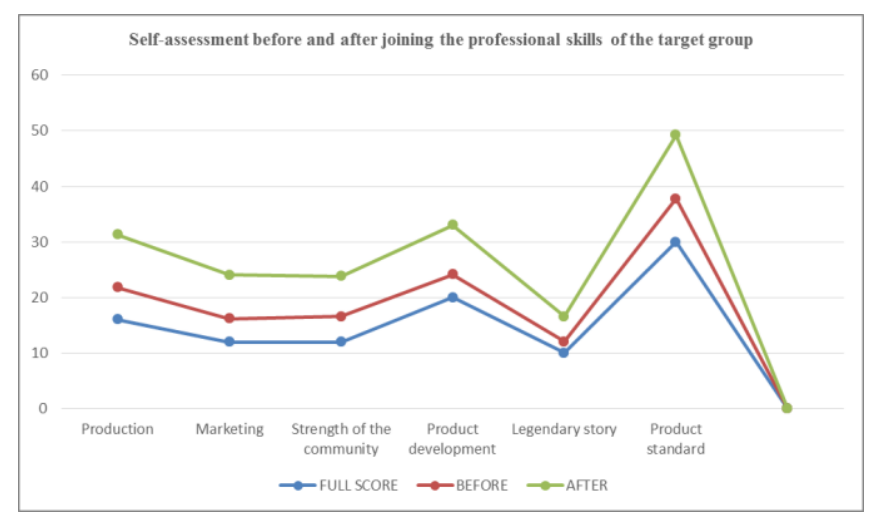

Fig. 2. Self-assessment before and after joining the professional skills of the target group.

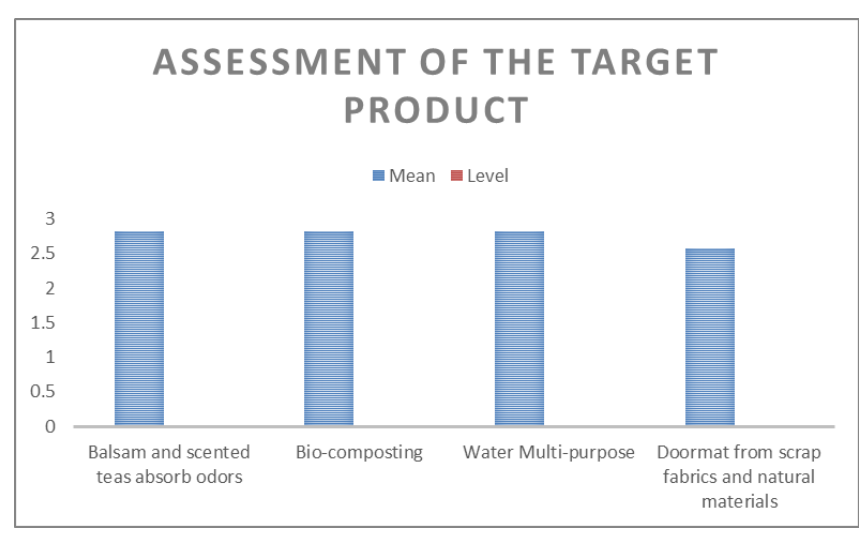

Fig. 3. Self-assessment of the target's product.

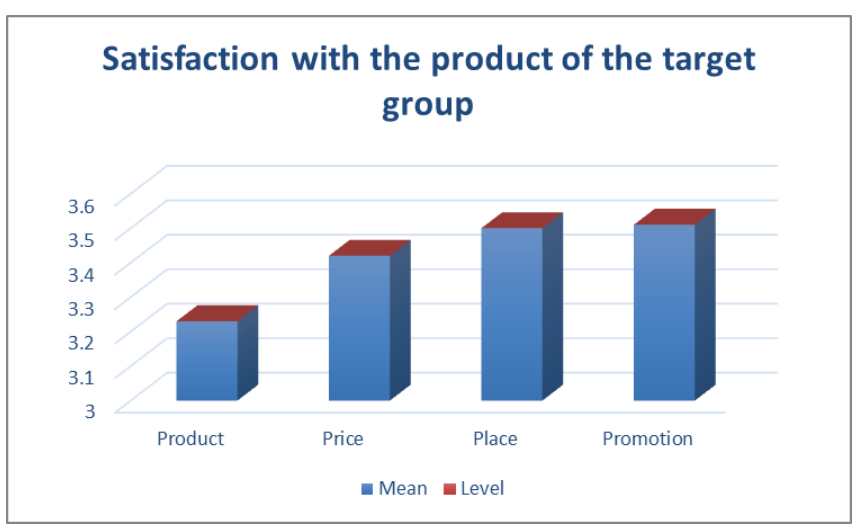

Fig. 4. Satisfaction with the product of the target group. 
This may be due settlement residents Mae Lao community is a community of socially disadvantaged. Although there are many agencies to assist and support the budget and professional skills training. But it is support, burning straw and old is the vehicle. Because it does not assess the impact will occur. No survey needs, no monitoring and evaluation at all which act as a political campaign. Is it bad to go without regard to the feelings of the people in the community settlement Mae Lao? But on the other hand to create problems in the society is to promote the wrong character until people get more accustomed to self-reliance. Never armed intellectual returns them to learn and achieve self-reliance. Instead, teach them to be dependent on others and wait to be rescued, but only when a team of researchers to survey the need and the possibility to develop and enhance true based on the facts and make sense of owning community. As well as build confidence and pride in their ability to analyze the strengths and weaknesses of the urban context and the potential to produce a settlement of people in Mae Lao to initiate a sufficiency economy approach, creating learning processes and activities. It is a way of life. Of such an approach to study the prospects for a strong body and mind power to develop themselves and their communities on a sustainable basis with a self-sufficient economic philosophy. This is consistent with the concept of Sumelt Tantivejakul (2006) [4] mentioned the importance and benefits of sufficiency economy of His Majesty about the social development of the country through Thailand weak. Because society does not create "Learning process" for most people with a lack of "intelligence" cannot solve problems by themselves. Combined with a lack of social opportunities often moral. Cause misconduct corruption at all levels. As well as the disadvantaged are being exploited. With economic development is modular, using "money" is "targeted" regardless of the consequences that follow such as the soil, water, forestry wisdom and culture. Finally, the high production costs of agricultural self-sufficiency and less. Various reasons attributed to the economic problems facing the country. The people in National self-reliance are not made public. His Majesty awareness and concern for the welfare of his subjects supremely Thailand have seen from His Majesty's "Sufficiency Economy" that has given them a second birthday in the year 1997 and 1998, which have been bending concept "Sufficiency Economy" to perform multiple agencies. The people understand that the economy is self-sufficient farmers in rural areas only, but actually a career like other merchants, officials and companies can lead works sufficiency to apply the "sufficiency economy" is like a pin piles before building a house, or in other words, forms the basis of home building firm before the next home or "sufficiency economy" is the foundation of a stable and sustainable life itself. Besides with the concept of Wong Cha-um, Sansern (2001) [5] mentioned the Sufficiency Economy stresses the middle path as an overriding principle for appropriate conduct by Thai people at all levels, from family to community to country. It calls for national development and administration to modernize in line with the forces of globalization. "Sufficiency" means moderation, reasonableness, and the need of self-immunity for sufficient protection from impact arising from internal and external changes. To achieve this, the application of knowledge with due consideration and prudence is essential. In particular, great care is needed at every step in the utilization of theories and methodologies for planning and implementation. At the same time, it is necessary to strengthen the moral fiber of the nation, so that everyone, particularly public officials, academics, and businessmen, adhere first and foremost to the principle of honesty and integrity. In addition, a way of life based on patience, perseverance, diligence, wisdom and prudence is indispensable to create balance and be able to cope appropriately with critical challenges, arising from extensive and rapid socioeconomic, environmental, and cultural changes in the world. This category comprises of literature related to moral/ethics, culture/custom, and local wisdom. Selected example is an article by Eaewsriwong (2000),[6] in which the author considered Sufficiency Economy as a culture and moral standard that emphasizes on non-greed and sharing, based on the interdependence principle among people and with nature. Eaewsriwong asserted that main objectives of Sufficiency Economy are to be sufficient of basic needs, while being sustainable in ecological system and lifestyles. Additionally, he convinced that sufficiency economy should be introduced and applied to both national and international levels, in which the world is presently dominated by consumerism and globalization culture. Including several Thai academics have contributed the work related to the conceptual interpretation of Sufficiency Economy philosophy. Samutvanich (1998) [7] asserted that the philosophy opened a new paradigm of thinking in a multi-dimensional and holistic term, while can be implemented step-by-step. Senanarong (1999) [8] emphasized that Sufficiency Economy implied self-reliance in 5 aspects: psychological, social, natural resources, technology and economy. Panthasein (1999) [9] proposed two conceptual papers: (1) a synthesis of Sufficiency Economy from economists' perspective; and (2) an analysis of Sufficiency Economy. He claimed that the Philosophy of Sufficiency Economy was based on Buddhist economics. Susangkarn (1999) [9] noted that the philosophy of Sufficiency Economy was consistent with neo-classical economics, by comparing moderation with diminishing marginal utility and reasonableness with rationality.

\section{CONCLUSIONS}

The development with community participation to improve the quality of life of those affected by their parents or relatives who are patients of leprosy settlement in Mae Lao. Analysis capabilities and marketing strategies targeted at education found that those with the need for all sectors to support and enhance the quality of their lives such as other social groups or communities, especially the potential for a career in the community. Including all sectors related to the dissolution of the term "settlement in Mae Lao" to reassure us about the adoption and get equal opportunities in society. As a result, these groups are constructed as all leprosy patients who make them a social impact. Because the general public is not acceptable and undesirable because they are mistaken for 
leprosy, a contagious disease and not everyone wants to get close, or ostracized. Of inferiority and a sense of frustration that makes those who have been affected by their parents or relatives who are patients of leprosy settlement in Mae Lao to be a sense of privacy which Mae Lao settlement owner is to develop unity is to be recognized by the people in their own society. Therefore, the total power by the creative community to join the community in all stages of development and a strong commitment to equality of opportunity in society by starting initiate sufficiency economy philosophy as a guide of lifestyle and settlement activities in Mae Lao community. As a result, learning participation and cooperation to resolve the differences in the group and everyone can work together very well. Having regard to the principles of human intelligence shows that we each have a unique ability to be able to discover the true capabilities are. If you have been encouraged and supported in the right way, it makes that person can show that their ability to get out. Because when the people join the group. We can learn from their own group that we have in any aptitude and training played a role together in a social group. Learn to work together and live together in a society where each person is an important part at all. Because each of us has different capabilities. But when living together in society, then society will contribute to the development has progressed well, with so gathered a team and be able to live together happily in society.

\section{ACKNOWLEDGMENT}

S. Pichedboonkiatrst respectfully requests that the National Research Council has provided financial support and respectfully thank all of the experts at the National Research Council has provided consulting advice to help well. The attentions to remedy defects were the good always.

S. Pichedboonkiatrst respectfully requests headman among the first and among the 11 officials of the Office of Disease Prevention and Control 10 local leaders, community leaders, women's groups and the elderly mother settlement Phan District, Chiang Rai Province, Mae Lao to better data collection in this research.

Finally, thanks to faculty, staff, and students at Rajamangala University of Technology Lanna, Chiang Rai help and encouragement in this research.

\section{REFERENCES}

[1] S. Mahannirunkul et al., "The quality of life in Thai people in economic crisis," Financial Support from the Department of Mental Health, Suan Pung Hospital Chiang Mai, 1998.

[2] P. Supinanon, "Audit analysis linking learning units and purpose learning with learning standard," Journal of Education Journal, September-December 2009.

[3] P. Wasi, Economy and Civil Society as a Way to Regain Economic Society, Bangkok, 1999.

[4] S. Tantivejakul, "Economic sufficiency," Journal Rajabhat Old, vol. 14 , no. 23 , pp. 1-50, 2006.

[5] W. C. Sansern Sufficiency Economy: Basis to theSustainable Development, Bangkok: Office of National Economic and Social Development Board (NESDB), 2001.

[6] N. Eaewsriwong, "Cultural dimension in Sufficiency Economy: its definition and importance," Silapra - Wattanadhamma Magazine, no. 4, pp. 78-86, February, 2000.

[7] C. Samutvanich, The Great Thinking Paradigm, Civil Services Training Institute, Special lecture. Bangkok, November. 1998.

[8] A. Senanarong, "A direction of rural development," in papers for Annual Conference of Development Research Institute, Khon Kaen University, January, 1999.

[9] C. Susangkarn, Sufficiency Economy and the Economic Crisis, Bangkok: Thailand Development Research Institute (TDRI), 1999.

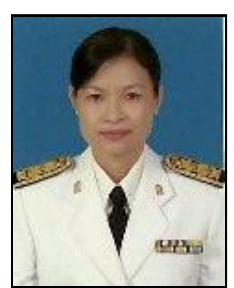

Sirichom Pichedboonkiatrst was born on August, 12, 1964 in Thailand. She received her Ph.D. in development education and minor in rural development at Central Luzon State University, Philippines in year 2003. She was an assistant director of academic affairs and assistant director of research and development. Her current job is the director of academic affairs and director of clinic technology at Rajamanggala University of Technology Lanna, ChiangRai campus, Thailand. Her research interest is based on integrated education and social science and she is an associate doctor and owns memberships in professional societies. She is also a committee member of Upper Northern Research Administration Network and a member of the association researchers. 